\title{
Early-Stage Design and Evaluation for Nuclear Power Plant Control Room Upgrades
}

\section{Proceedings of the Human Factors and Ergonomics Society Annual Meeting 2014}

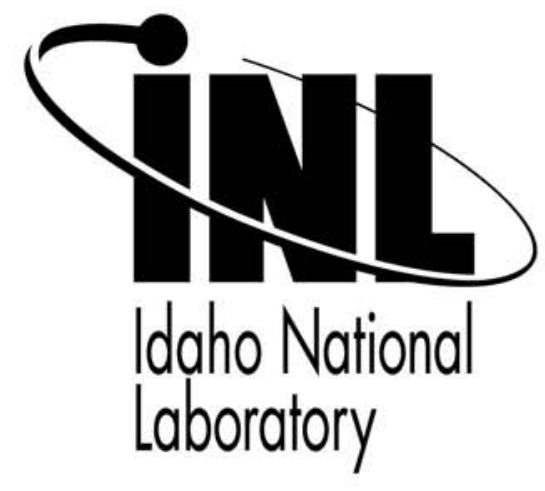

\section{Ronald L. Boring, Jeffrey C. Joe, Thomas A. Ulrich and Roger T. Lew}

\section{October 2014}

This is a preprint of a paper intended for publication in a journal or proceedings. Since changes may be made before publication, this preprint should not be cited or reproduced without permission of the author. This document was prepared as an account of work sponsored by an agency of the United States Government. Neither the United States Government nor any agency thereof, or any of their employees, makes any warranty, expressed or implied, or assumes any legal liability or responsibility for any third party's use, or the results of such use, of any information, apparatus, product or process disclosed in this report, or represents that its use by such third party would not infringe privately owned rights. The views expressed in this paper are not necessarily those of the United States Government or the sponsoring agency. 


\section{Proceedings of the Human Factors and Ergonomics Society Annual Meeting http://pro.sagepub.com/}

\section{Early-Stage Design and Evaluation for Nuclear Power Plant Control Room Upgrades}

Ronald L. Boring, Jeffrey C. Joe, Thomas A. Ulrich and Roger T. Lew

Proceedings of the Human Factors and Ergonomics Society Annual Meeting 2014 58: 1909

DOI: $10.1177 / 1541931214581399$

The online version of this article can be found at:

http://pro.sagepub.com/content/58/1/1909

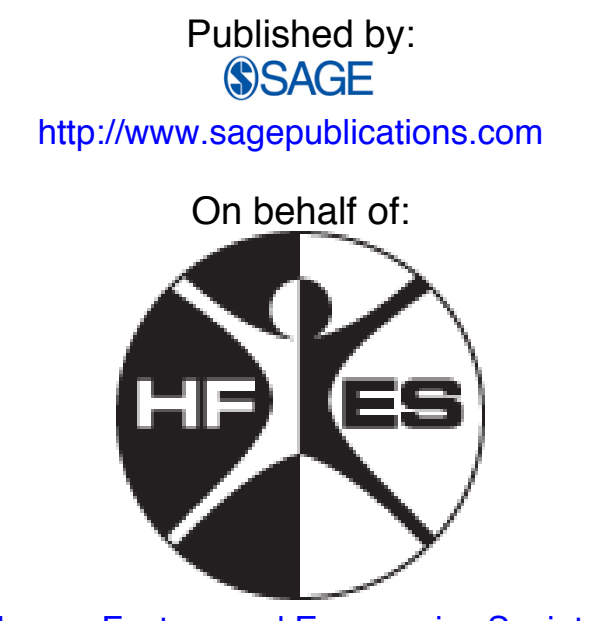

Human Factors and Ergonomics Society

Additional services and information for Proceedings of the Human Factors and Ergonomics Society Annual Meeting can be found at:

Email Alerts: http://pro.sagepub.com/cgi/alerts

Subscriptions: http://pro.sagepub.com/subscriptions

Reprints: http://www.sagepub.com/journalsReprints.nav

Permissions: http://www.sagepub.com/journalsPermissions.nav

Citations: http://pro.sagepub.com/content/58/1/1909.refs.html

> Version of Record - Oct 17, 2014

What is This? 


\title{
EARLY-STAGE DESIGN AND EVALUATION FOR NUCLEAR POWER PLANT CONTROL ROOM UPGRADES
}

\author{
Ronald L. Boring, Jeffrey C. Joe, Thomas A. Ulrich, and Roger T. Lew \\ Idaho National Laboratory, Idaho Falls, Idaho 83415
}

\begin{abstract}
As control rooms are modernized with new digital systems at nuclear power plants, it is necessary to evaluate operator performance with these systems as part of a verification and validation process. While there is regulatory and industry guidance for some modernization activities, there are no well defined standard processes or predefined metrics available for assessing what is satisfactory operator interaction with new systems, especially during the early design stages. This paper proposes a framework defining the design process and metrics for evaluating human system interfaces as part of control room modernization. The process and metrics are generalizable to other applications and serve as a guiding template for utilities undertaking their own control room modernization activities.
\end{abstract}

\section{CONTROL ROOM MODERNIZATION}

Main control room (MCR) modernization is a necessity at nuclear power plants (NPPs). With life extensions of plants beyond the original 40 -year operating licenses, there is strong impetus to upgrade aging systems to achieve greater efficiencies and maintain high operational reliabilities. Since existing MCRs in United States (U.S.) plants are largely analog or mechanical systems and since equivalent analog or mechanical replacements for these systems cannot be readily obtained, modernization comes in the form of digital upgrades. In particular, utilities are replacing individual analog systems on the control boards with distributed control systems (DCSs) featuring digital displays, programmable logic controllers, and alphanumeric and touch input devices. These upgrades have to date been centered on non-safety systems, which do not require extensive license modifications through the U.S. Nuclear Regulatory Commission (NRC). Nonetheless, because the humansystem interaction (HSI) between the operators and the DCS is considerably different than the analog systems it replaces, it is prudent to undertake a thorough process of ensuring the utility and performance of the new systems.

Because of the central role the operator plays in using the upgraded HSIs in the MCR, it is crucial that utilities properly design and evaluate their new systems using a vetted human factors engineering (HFE) process. However, currently available guidance on HFE for NPPs either does not address control room modernization (instead focusing on new builds) or doesn't explain how to use an iterative design-evaluation process that provides early stage feedback on a novel design. This paper provides practical guidance and a framework for combining early-stage design with verification and validation in the upgrade of an MCR.

\section{NUREG-0711 FRAMEWORK}

The U.S. Nuclear Regulatory Commission (NRC) publishes the Human Factors Engineering Program Review model in NUREG-0711, Rev. 3 (O'Hara et al., 2012). The purpose of NUREG-0711 is to provide the procedure by which U.S. NRC staff review the effectiveness of human factors activities related to new construction and license amendments. Title 10, Parts 50 and 52, of the Code of Federal Regulations (10 CFR 50 and 52) provide the legal basis for requiring human factors considerations in nuclear power plant main control rooms. NUREG-0711 further defines human factors engineering as "The application of knowledge about human capabilities and limitations to designing the plant, its systems, and equipment." Put succinctly, NUREG-0711 outlines the process utilities must follow to ensure that control rooms support the activities operators need to perform safely and efficiently.

NUREG-0711, Rev. 3, contains four general categories of activities, ranging from planning and analysis, design, verification and validation $(\mathrm{V} \& \mathrm{~V})$, and implementation and operation. Each of these phases is described below:

- The planning and analysis phase gathers information on the system, functions, tasks, and operator actions, which help to define the requirements for the new system being implemented.

- These requirements, in turn, drive the second category of activities, related to iterative design of the new or modified system. The requirements are turned into a style guide and specification, which is then translated into the actual HSI.

- After the system design is finalized, it must undergo verification and validation to ensure that the system works as intended. Importantly, from a human factors perspective, the system should also be usable by the target users of the system, which are reactor operators in the case of the MCR. V\&V remains an area of confusion in the field of human factors, as the distinction between verification and validation is not always clear. Fuld (1997) suggests that verification entails confirming existing truths, while validation involves confirming performance. This can be understood simply to mean that verification involves checking the HSI against an existing human factors standard like NUREG-0700 (U.S. NRC, 2002), while validation requires checking the performance of the 
system and operators according to desired performance criteria.

- $\quad$ Finally, the system must be implemented and operated, which includes monitoring operator performance in the actual use of the system.

While NUREG-0711, Rev. 3, is an invaluable guide to the regulator as well as a roadmap for many human factors activities by the licensee, it falls short of addressing three critical areas:

1. Types of Testing Specified: Chapter 8 of NUREG-0711, Rev. 3, outlines the required process for HSI design. The current version briefly references performing evaluations in the design phase-prior to V\&V-but doesn't give detailed guidance. Specifically, Section 8.4.6 suggests there are two types of tests and evaluations that are appropriate during the design phase:

- Trade-off evaluations, in which different design alternatives are considered, and

- Performance-based tests, in which operator performance is assessed.

These two are not mutually exclusive, e.g., performance-based tests can be used as part of trade-off evaluations. NUREG-0711 does not specifically require tests and evaluations during the design phase, nor does it provide examples of how such approaches are useful in shaping the design of the HSI. NUREG-0711 does require evaluation as part of the $\mathrm{V} \& \mathrm{~V}$ activities conducted after the design phase. In particular, it advocates integrated system validation (ISV), which is "an evaluation, using performance based tests, to determine whether an integrated system's design (i.e., hardware, software, and personnel elements) meets performance requirements and supports the plant's safe operation" (O'Hara et al., 2012, p. 73). ISV is further elaborated in the earlier NUREG/CR-6393, (O'Hara et al., 1995). Note that NUREG/CR-6393 specifically states in Section 4.1.3 that the general evaluation methods used for ISV should not be used during earlier design phase activities, since they have different underlying goals. The ISV approach in NUREG-0711 and NUREG/CR-6393 has garnered criticism in terms of the limits of how well one set of test results can generalize to every possible subsequent situation (Fuld, 2007), an argument that could be extrapolated to suggest more frequent tests earlier in the process may generalize better. Still, an emerging consensus maintains verification works very well at the tail-end of design, while validation needs to be conducted earlier and iteratively (see, for example, Hamblin et al., 2013).

2. Non-Safety Systems: NUREG-0711 provides extensive guidance in Section 8.4.4.2 on control room requirements, but these requirements refer to overall systems - especially safety systems - that need to be present in the control room at design time. However, there is no guidance on individual non-safety systems. While non-safety systems (e.g., turbine control) are not subject to the same level of regulator review as safety systems (e.g., reactor control), a standardized set of good practices across both applications is desirable. There is no guidance on how to scale the approach to non-safety systems, including differences in the level of rigor expected.

3. Modernization: Finally, it must be noted that NUREG0711 is optimized for reviewing initial license submittals (e.g., new builds) or license amendments (e.g., changing the operating characteristics of an existing required safety system). NUREG-0711 fails to provide clear guidance on modernization-replacement of an existing non-safety system-except to say that it should reasonably conform to operator expectations to minimize the need for additional training

Because guidance is missing on how to apply human factors engineering for modernization efforts on the existing fleet, the goal of this report is to augment the guidance in NUREG-0711 specifically to address how to upgrade existing HSIs for non-safety systems as part of a NUREG0711 compliant (albeit unrequired) process. Note that this approach to augmenting NUREG-0711 has to date not been reviewed or endorsed by the U.S. NRC.

\section{EPRI GUIDANCE}

The Electrical Power Research Institute (EPRI) has published useful guidance on development of a human factors engineering process in support of control room modernization. Human Factors Guidance for Control Room and Digital Human-System Interface Design and Modification: Guidelines for Planning, Specification, Design, Licensing, Implementation, Training, Operation, and Maintenance, TR-1010042 (EPRI, 2005) provides thorough discussions on a number of relevant steps in modernization, including control room modernization related to hybrid control room upgrades.

Section 3.8 of EPRI-TR-1010042 emphasizes that these activities should be performed not as a single step after the design process but as a parallel activity coinciding with design. Important steps in the assessment prior to the final ISV include:

- 3.8.3.2: Verification activities performed by designers and validation by independent human factors experts

- 3.8.3.3: Review of HSI elements (e.g., location of displays, readability of graphical elements on displays, etc.)

- 3.8.3.4: Task support verification in which representative tasks to be performed on the system are tested with operators using either static or dynamic HSI display elements

- 3.8.3.5: Design verification of the finalized HSI against design specifications and standards

- 3.8.3.6: Operational conditions sampling, in which key aspects of personnel tasks, plant conditions, and situations as determined in the planning and analysis 
phase (e.g., especially from the operating experience review) are tested

Within these suggestions, ERPI-TR-1010042 provides suggestions for performance measures in Section 3.10.3.6. These include measures to catalog the actions carried out by the operators (e.g., responding to an alarm or navigating between displays), measures of task performance (e.g., time and accuracy to complete a given task of interest), and subjective measures (e.g., operator opinions on facets of the HSI).

EPRI-TR-1010042 provides helpful additional detail not covered in NUREG-0700, tailored to the specific task of control room modernization. It also emphasizes the importance of ongoing $\mathrm{V} \& \mathrm{~V}$ activities as part of the design process and not simply as an end-state activity to be completed after the design is finalized and implemented.

\section{A SIMPLIFIED EVALUATION FRAMEWORK}

As noted, NUREG-0711 does not provide guidance for conducting HSI evaluations during the design phase. Here, we outline a simplified framework to redress this shortcoming and to provide the context and methods suitable for early stage HSI evaluation in support of NPP control room modernizations. The key idea featured here is that of the iterative design cycle - one in which HSIs are designed, prototyped, tested, and improved in a cyclical fashion (Nielsen, 1993). Iterative design is crucial to the usercentered design process found in International Standards Organization (ISO) Standard 9241 that is at the heart of most human factors design activities (International Standards Organization, 2010). A core tenet of iterative design is that the resulting HSI be more usable when built through a repeated design and evaluation process involving early testing rather than built to completion and then tested. Feedback provided early in the design process helps to ensure that error traps in the HSI are eliminated rather than ingrained in the design, meaning it is easier to fix usability issues earlier in the design than as a fix after the design is finalized. In terms of control room modernization, the equivalent argument would be that evaluation incorporated into the design phase will produce a system more acceptable, efficient, and useful to operators rather than one built with separate design and V\&V phases. The approach we advocate includes $\mathrm{V} \& \mathrm{~V}$ activity at the end of the design process but also incorporates small-scale V\&V activities in conjunction with design milestones. Thus, V\&V becomes a staged activity rather than a single terminating activity after the completion of the design.

Figure 1 illustrates the idea of performing V\&V activities prior to the formal ISV. In the depiction, the software specification and HSI style guide are developed based on information obtained in the planning and analysis phase. The software is then developed along three milestones within the design phase:

- At the first milestone (the 30\% completion mark), the preliminary screen designs are completed. These screens can be evaluated as static screens by obtaining feedback from operators and experts on their impressions of the screen layout, look and feel, and completeness of information.

- $\quad$ At the second milestone (the $70 \%$ completion mark), the system dynamics are completed, and an initial functional prototype of the system may be evaluated by experts and operators. At this stage, operator performance with the system may be assessed.

- At the final milestone (the $100 \%$ completion mark), the system may be tested a final time (in what might be called a dry-run or pre-ISV). If there is sufficient confidence in the results of the two earlier evaluations, it may be appropriate to go directly to the ISV.

ISV is, by definition, summative, and it can be concluded that the guidance in NUREG-0711 is primarily of value to summative evaluations. What, then, of evaluations performed prior to ISV or design verification (i.e., formative evaluations)? Table 1 outlines different verification and validation methods suitable for formative and summative evaluation. Verification is accomplished by expert review against a standard set of criteria, while validation is performed via user testing. The following considerations apply:

- Formative Verification: Completed during the design phase by expert review. Typical for this type of evaluation would be heuristic evaluation, which is evaluation of the system against a pre-defined, simplified set of characteristics such as a usability checklist (Ulrich et al, 2013).

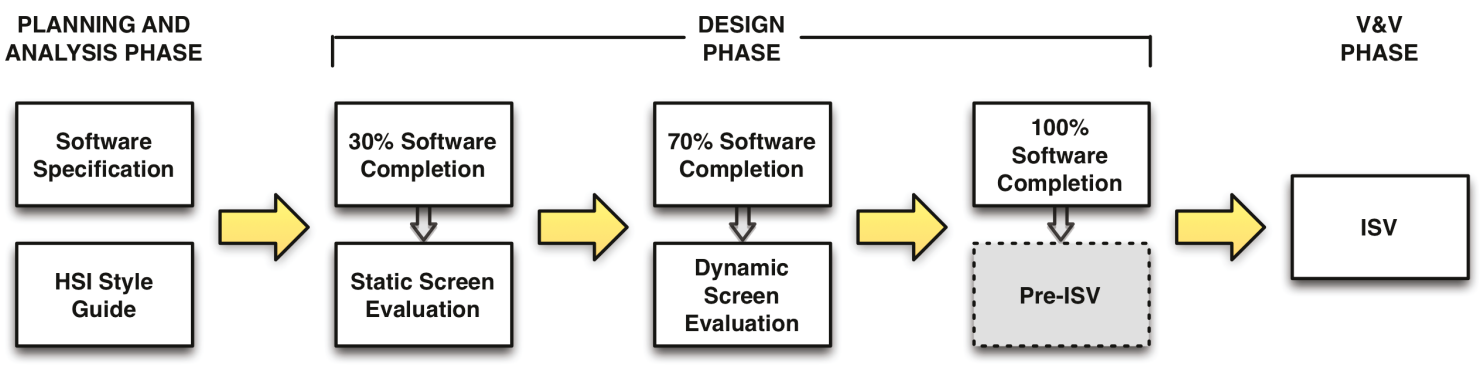

Figure 1. An Example of Design Phase Evaluations and Milestones. 
Table 1. Verification and Validation for Formative and Summative Evaluations.

\section{Evaluation Phase}

\begin{tabular}{|c|c|c|}
\hline & Formative & Summative \\
\hline $\begin{array}{c}\text { Expert Review } \\
\text { (Verification) }\end{array}$ & $\begin{array}{l}\text { Heuristic } \\
\text { Evaluation }\end{array}$ & $\begin{array}{l}\text { Design } \\
\text { Verification }\end{array}$ \\
\hline $\begin{array}{l}\text { User Testing } \\
\text { (Validation) }\end{array}$ & Usability Testing & $\begin{array}{c}\text { Integrated } \\
\text { System Validation }\end{array}$ \\
\hline
\end{tabular}

- Summative Verification: Completed after the design phase by expert review. Typical for this type of evaluation would be a review against applicable standards like NUREG-0700 (O'Hara et al., 2002) or requirements like an HSI style guide.

- Formative Validation: Completed during the design phase by user testing. Typical for this type of evaluation would be usability testing of a prototype HSI (ISO 9241, 2010).

- Summative Validation: Completed after the design phase by user testing. Typical for this type of evaluation would be integrated system validation as described in NUREG-0711 (O’Hara et al., 2012).

\section{HUMAN PERFORMANCE CONSTRUCTS AND METRICS}

No framework to evaluate HSIs in MCR modernization activities would be complete without guidance on theoretical constructs and metrics. As utilities engage in modernization activities, they need to be able to evaluate operator performance as they interact with new digital HSIs. While there is a standard for the human-centered design of systems (ISO 9241, 2010), there is no publicly available and widely disseminated standard template of metrics available to utilities to help determine what is satisfactory operator interaction with modernized components of an NPP MCR. Thus, this section presents a brief overview of what theoretical constructs of usability, metrics, and measures a utility can use to assess usability issues in their control room modernization activities. This section also describes factors that help utilities choose which constructs and metrics to use, depending on regulatory considerations, the type of usability study being conducted, the usability study's goals, the target user, the testing environment and equipment, and other resource constraints.

Some of the common human factors theoretical constructs of usability include:
1. Task success: Assessing the extent to which the user (or operator) is able to accomplish their task goal(s).

2. Task time: How long it takes a user to complete a task.

3. Efficiency: How quickly and with what level of effort the user exerts to accomplish the task.

4. Satisfaction: How pleased the user is with their experience interacting with the system.

5. Errors: Assessing the user's performance relative to success/failure criteria. Errors can be incorrect actions that contribute to task failure, or failures to act when action would have avoided task failure.

6. Learn-ability: How quickly a novice user is able to use a new system effectively.

All of these constructs assess important dimensions or aspects of usability. The extent to which a system facilitates the user's ability to efficiently complete tasks using an interface that minimizes human errors, is satisfying to use, and easy to learn is the extent to which it can be called usable.

With respect to measuring these usability constructs, the possible set of measurement tools includes: self-reported metrics (e.g., surveys, interviews, etc.), behavioral measures, physiological measures (e.g., eye tracking), simulator logs, and combined issues-based metrics, which are the aggregated frequency count of all of the usability issues the other metrics detect. More details about usability constructs and metrics can be found in Tullis and Albert (2008), Dumas and Redish (2002), and Rubin (1994), among other sources.

Given the number of constructs and metrics available for use, it is important to keep in mind that not all of them are applicable to the kinds of usability studies that can and should be conducted for NPP MCR modernization. Only certain kinds of studies can be conducted at certain points in the design process. As such, depending on what stage the utility is at in their modernization activities, some usability studies and their companion constructs and metrics are appropriate while others are not. Using the framework proposed in Table 1 helps select the appropriate constructs 
and metrics. For example, verification, whether formative or summative, can use all usability constructs and metrics, since this expert review will primarily extract the expert's insights on operator performance, but other external factors such as cost and schedule also need to be considered. Validation may also avail itself of all usability constructs and metrics, but for formative evaluations of early prototypes, it is often desirable to use only self-report and behavioral measures to assess the usability constructs. Summative reviews typically involve more detailed analyses and may establish formal acceptance criteria, since the focus shifts from discovering what users think about the system and interface to measuring their performance objectively. In addition, usability testing and ISV require more resources than heuristic evaluation or design verification. Usability testing and ISV both require knowledgeable operators as participants in the evaluation. Usability testing and ISV require at least a part-task simulator, and produce better results as the fidelity and scope and size of the simulator increases.

In general, the following criteria should be factored into the selection of usability constructs and metrics:

- The type of usability study (see Table 1)

- The goal(s) of the study

- Regulatory considerations (i.e., which constructs and metrics will demonstrate satisfactory operator interaction with the new system)

- Availability and/or accessibility of technology and experimental equipment to conduct the usability study (e.g., it may not be feasible to bring some physiological measurement equipment such as eye tracking into a simulator)

- $\quad$ Budget, schedule, and availability of expert end-users (e.g., licensed operators), and human factors experts to conduct the study

\section{CONCLUSIONS}

Current guidance for HFE in support of control rooms is either focused primarily on design and evaluation for new builds or evaluation at the tail-end ISV phase. There is a need, however, to address HFE for control room upgrades and to incorporate earlier evaluation in the design cycle. By providing practical guidance on early stage design evaluation in support of control room modernization, this paper has answered two main objectives:

- To emphasize the importance of evaluation as an ongoing activity that supports design, not follows it

- To demonstrate a graded approach to HFE in which a practicable, reasonable, and cost-effective process is used to support control room modernization.

By understanding the opportunities for both verification and validation across the design life cycle of the upgrade, utilities will find a systematic and readily extensible process that ensures the success of the HSI when embarking on control room upgrades.

\section{DISCLAIMER}

This work of authorship was prepared as an account of work sponsored by an agency of the United States Government. Neither the United States Government, nor any agency thereof, nor any of their employees makes any warranty, express or implied, or assumes any legal liability or responsibility for the accuracy, completeness, or usefulness of any information, apparatus, product, or process disclosed, or represents that its use would not infringe privately-owned rights. Idaho National Laboratory is a multiprogram laboratory operated by Battelle Energy Alliance LLC, for the United States Department of Energy under Contract DE-AC07-05ID14517.

\section{REFERENCES}

Dumas, J.S. and Redish, J.C. (1999/1993) A Practical Guide to Usability Testing. Bristol, UK: Intellect.

Electrical Power Research Institute. (2005). Human Factors Guidance for Control Room and Digital Human-System Interface Design and Modification, 1010042. Palo Alto: Electrical Power Research Institute.

Fuld, R.B. (1997) 'Verification and validation: what's the difference?', Ergonomics in Design, Vol. 5, No. 3, pp. 28-33.

Fuld, R.B. (2007). On system validity, quasi-experiments, and safety: A critique of NUREG/CR-6393. International Journal of Risk Assessment and Management, 7, 367-381.

Hamblin, C., Cataneda, M., Fuld, R.B., Holden, K., Whitmore, M., and Wilkinson, C. (2013). Verification and validation: Human factors requirements and performance evaluation. Proceedings of the Human Factors and Ergonomics Society 57th Annual Meeting, 2032-2036.

International Standards Organization. (2010). Ergonomics of Human-System Interaction-Part 210: Human Centred Design for Interactive Systems, ISO 9241-210. Geneva: International Standards Organization.

Nielsen, J. (1994). Enhancing the explanatory power of usability heuristics. Computer-human interaction conference proceedings, 152-158. Boston, ACM.

O’Hara, J.M., Higgins, J.C., Fleger, S.A., and Pieringer, P.A. (2012). Human Factors Engineering Program Review Model, NUREG-0711, Rev. 3. Washington, DC: U.S. Nuclear Regulatory Commission.

O’Hara, J.M., Brown, W.S., Lewis, P.M., and Persensky, J.J. (2002). Human-System Interface Design Review Guidelines, NUREG-0700, Rev. 2. Washington, DC: U.S. Nuclear Regulatory Commission.

O'Hara, J., Stubler, W., Higgins, J., and Brown, W. (1995). Integrated System Validation: Methodology and Review Criteria, NUREG/CR6393. Washington, DC: U.S. Nuclear Regulatory Commission.

Redish, J., Bias, R.G., Bailey, R., Molich, R., Dumas, J., and Spool, J.M. (2002). Usability in practice: Formative usability evaluationsEvolution and revolution. Proceedings of the Human Factors in Computing Systems Conference (CHI 2002), 885-890.

Rubin, J. (1994). Handbook of Usability Testing: How to Plan, Design, and Conduct Effective Tests. New York, NY: John Wiley \& Sons.

Tullis, T. and Albert, W. (2008). Measuring the User Experience: Collecting, Analyzing, and Presenting Usability Metrics. Elsevier/Morgan Kaufmann, Burlington, MA.

Ulrich, T., Boring, R., Phoenix, W., DeHority, E., Whiting, T., Morrell, J., and Backstrom, R. (2012). Applying Human Factors Evaluation and Design Guidance to a Nuclear Power Plant Digital Control System, $I N L / E X T-12$ - 26797. Idaho Falls: Idaho National Laboratory. 